Document downloaded from:

http://hdl.handle.net/10251/38234

This paper must be cited as:

Pastor Soriano, JV.; Payri, R.; Salavert Fernandez, J.; Manin, J. (2012). Evaluation of natural and tracer fluorescent emission methods for droplet size measurements in a diesel spray. International Journal of Automotive Technology. 13(5):713-724. doi:10.1007/s12239012-0070-z.

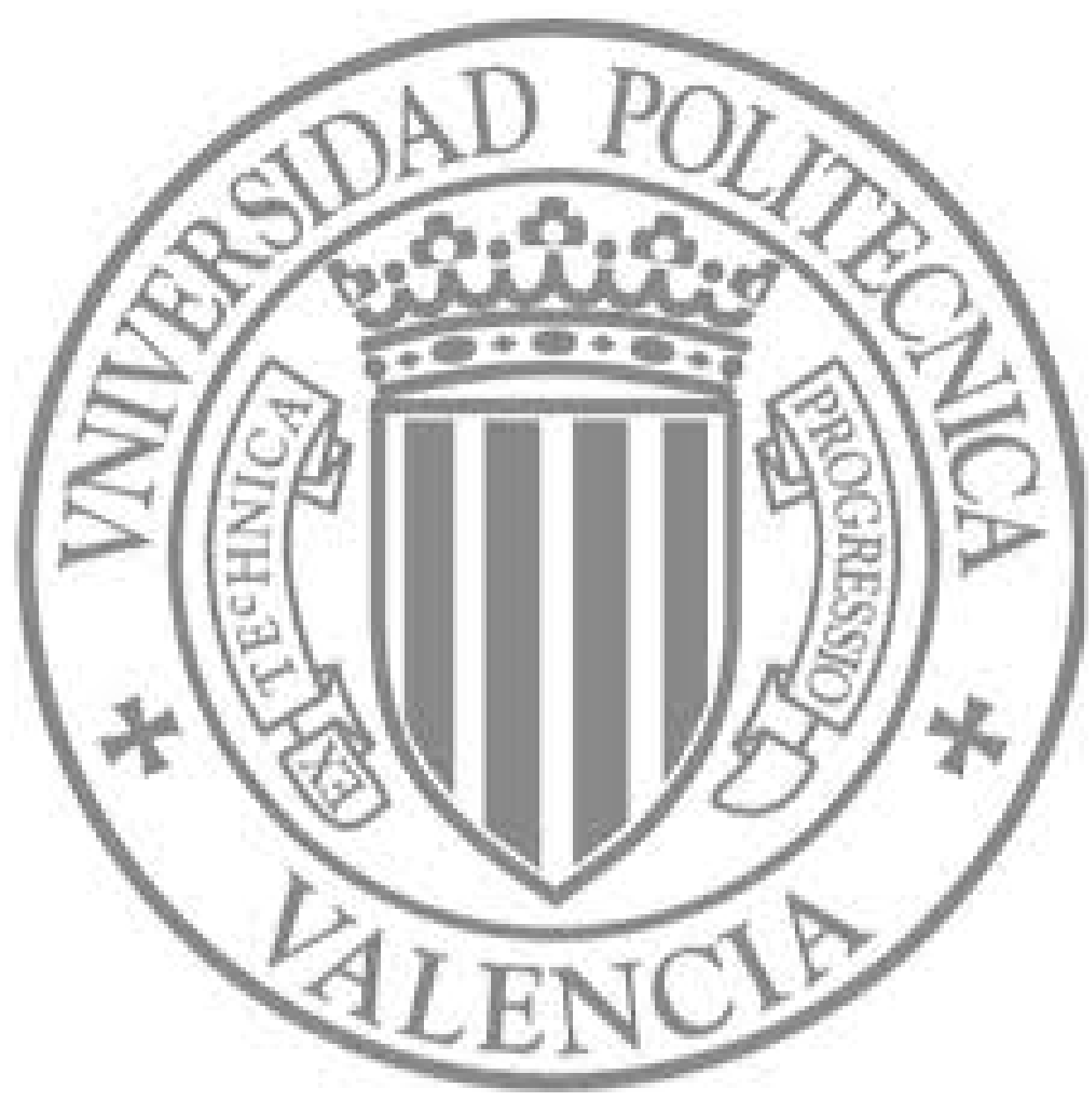

The final publication is available at

http://link.springer.com/article/10.1007\%2Fs12239-012-0070-z

Copyright Springer Verlag (Germany) 


\section{Evaluation of natural and tracer fluorescent emission methods for droplet size measurements in a Diesel spray}

Pastor J. V., Payri R. (rpayri@mot.upv.es), Salavert J.M.

CMT - Motores Térmicos, Universidad Politécnica de Valencia, Spain

Manin J.

Sandia National Laboratories, 7011 East Ave, Livermore, CA

ABSTRACT - Spray sizing recording the fluorescent emission and the scattered light has been widely applied for spray diagnostics in the last two decades. Different experimental strategies have been developed, however, comparing the different solutions offered always presents an interest for experimentalists. In this work, a comparison of two fluorescence strategies for measurement of the droplet size in the liquid phase of a last generation DI diesel spray is done. The natural fluorescent emission of a commercial diesel fuel and the fluorescence emitted by a tracer (Rhodamine B) are set against through theoretical and experimental approaches. The LIF/Mie ratio commonly called Planar Droplet Sizing (PDS) technique is applied in two different ways to make the light on the advantages of using a fluorescent dopant or not. The sprays have been injected under non-evaporative conditions into a constant pressure vessel that simulates densities present at the moment of the injection in current passenger cars diesel engines. A characterization of the signal properties has been performed through measurements of absorption coefficient, fluorescence emission spectrum, quantum yield and lifetime for both configurations. The scattered light and fluorescence intensities have been calculated to verify the dependencies with droplet surface and volume. The results, when applying the two techniques to quantify droplet size in dense diesel sprays, show that the weakness of the signal and the lack of control on the properties of the natural fluorescence produce distortion of the shape of the spray and make the measurements unreliable. 
KEYWORDS - diesel spray, Sauter Mean Diameter (SMD), Laser-Induced Fluorescence (LIF),

Rhodamine B, fluorescence quantum yield.

\section{INTRODUCTION}

The mixing process between fuel and oxidizer is one of the main parameters for the quality of combustion (Kim et al. 2011). In a direct injection engine, the characteristics of the spray determine the air/fuel mixing in the combustion chamber (Lee et al. 2010). Direct studies on the diesel spray in its usual environment, i.e. the engine, are complicated because they require special optical accesses, and running such prototype engines always needs special and expensive equipment. For this reason studying the spray outside the engine in steady and controlled conditions has always been of special interest.

The spray behavior and its structure are influenced by several parameters related to the environment in which the spray is injected and other parameters inherent to the injection system (Payri et al. 2005, Benajes et al. 2010, Lee et al. 2005). Studies aiming to characterize the spray can consider two different approaches: microscopic and macroscopic. The aim of the first category is to provide internal spray features such as droplet size and velocity (Albrecht et al. 2003), as well as mass distribution (Ramirez et al. 2009). Geometric features, i.e. spray tip penetration, cone angle are determined with macroscopic measurements, basically spray imaging (Naber and Siebers 1996).

Planar Laser-Induced Fluorescence (Planar LIF or PLIF) (Eckbreth 1988) offers a relatively simple alternative to microscopic techniques, while providing the experimentalist with basic geometric information. Used either for gases or liquids, it relies on the fact that the quantity (or mass) of the substance under study is proportional to its fluorescent emission; therefore the concentration can be obtained (assuming proper mixture of the fluorescent substance). The droplet size can also be obtained by dividing the fluorescence intensity by the Mie signal, which 
in its turn depends on droplet surface (LeGal et al. 1999, Domann and Hardalupas 2002) (see eq. 3). Proposed by Yeh et al. (1993), this technique assumes surface dependence with droplet diameter for the elastically scattered light signal and volume dependence for the fluorescent emission.

Since then, many researchers concentrated their efforts on this field and spray analysis using the LIF/Mie ratio became more and more important (Lockett et al. 1998, Greenhalgh et al. 1999, Charalampous and Hardalupas 2011). For example, Domann and Hardalupas (2000) published a study aiming at guiding researchers through the application of this technique then called the Planar Droplet Sizing (PDS). A methodology for concentration measurements of diesel sprays in isothermal conditions using the natural fluorescence emitted by a commercial diesel fuel has been described by Pastor et al (2002). The authors stated that the losses due to multiple Mie scattering resulted in severe asymmetrical spray concentration maps and that important corrections were needed (Pastor et al. 2009).

The objective of this paper is to determine which fluorescence signal, natural or from an additive, would represent a better solution for liquid spray analysis from a qualitative/quantitative point of view. The experiments conducted for the natural fluorescence followed those described by Pastor et al. (2002), while the methodology relying on doping the fuel is fully described in the following pages. A brief introduction to the theoretical side of these experiments is presented after this introduction, along with the important parameters to consider when applying such optical diagnostics. The experimental equipment and setup used in this work are presented in the third section. Then, specific tests aiming at understanding the fluorescence emission for both the natural and Rhodmanine B cases have been undertaken providing measurements of the fluorescence quantum yield and lifetime, as well as the absorption coefficient. The following section presents a computational analysis of the signals collected to check the validity of the hypotheses concerning Mie scattering and fluorescence emission. The result section offers a direct comparison of the two techniques; for that purpose, 
2-D intensity of Mie, fluorescence and SMD maps are presented. An exploration of different operating conditions is also carried out and the results applying the preferred technique are presented before ending the present paper with the main outcomes of this study.

\section{THEORETICAL BACKGROUND}

Fluorescence is a property of some atoms and molecules to absorb light at a particular wavelength and to subsequently emit light over a longer wavelength range (Lakowicz 2006). From a practical point of view, the fluorescence phenomenon can be briefly explained as the reemission of part of the incident radiation at a longer wavelength when some substances, called fluorophore, are illuminated. The intensity of the emitted fluorescence is dependent upon several parameters and must be accurately known when applying diagnostics based on the fluorescent emission. The fluorescence quantum yield $\Phi$ is one of these parameters and corresponds to the ratio of photons absorbed to photons emitted through fluorescence (Schulz and Sick 2005). By integration over the volume of a droplet, taking into account the scattering processes such as external reflection, multiple internal reflections, transmission and surface waves, the fluorescence emitted by one droplet can be computed. To do so, the Beer-Lambert law is generally used as it provides the intensity of light after extinction through a liquid (Payri et al. 2011):

$$
\frac{\mathrm{I}}{\mathrm{I}_{0}}=\mathrm{e}^{-\tau}
$$

Where $\tau$ is the optical depth, $I$ and $I_{0}$ are the transmitted and incident intensities, respectively. The optical depth can be decomposed in: 


$$
\tau=\alpha \cdot L_{\mathrm{opt}}
$$

Equation 2 is only valid for extinction processes considering absorption as the only source of extinction (i.e. no scattering process), which is most likely to be true for extinction in liquid. In this expression, $\alpha$ is the absorption coefficient and $L_{\text {opt }}$ the optical pathways through the liquid (droplet).

For measurements in sprays, the extinction is mostly due to scattering and equation 2 has to be modified accordingly. In this case, the number of droplet (number density) and their diameter (scattering cross-section) would replace the absorption coefficient in this formulation. Therefore, the intensity of the scattered light depends upon the droplet surface (square diameter) (LeGal et al. 1999, Jermy et al. 2000). On the other hand, several authors observed and reported that the intensity of the fluorescent emission was proportional to the volume of the droplet (diameter to the cube) (LeGal et al 1999, Domann and Hardalupas 2001).

The droplet sizing technique presented in the introduction and being the subject of this paper is achieved by combining both Mie scattering and fluorescence signals (LeGal et al. 1999, Domann and Hardalupas 2002, Charalampous and Hardalupas 2011). This hypothesis is only valid if the signal emitted by the fluorophores is dependent upon the cube of the diameter whilst the elastically scattered light is dependent on the square of the diameter such that the following expression is verified (LeGal et al. 1998, Jermy et al. 2000):

$$
\frac{S_{\mathrm{LF}}}{S_{\mathrm{N}: 1 \mathrm{l}}} \propto \frac{\Sigma_{1} D_{1}^{3}}{\Sigma_{1} D_{1}^{2}}=\mathrm{SMD}
$$

Where $D$ is the geometrical droplet diameter, $S_{L I F}$ and $S_{M i e}$ are the acquired signal for LIF and Mie, respectively. If this assumption is verified, then the pixel to pixel ratio of two images of a large ensemble of droplets should provide a map of Sauter Mean Diameter. 


\section{GENERATION OF SPRAYS AND OPTICAL EQUIPMENT}

\subsection{High-density chamber and injection system}

The sprays have been injected in an optically accessible constant volume vessel filled with sulfur hexafluoride gas $\left(\mathrm{SF}_{6}\right)$ to simulate real engine densities with relatively low pressure. $\mathrm{SF}_{6}$ is an inert gas whose viscosity and optical properties are very similar to those of air (Pastor et al. 2002). The experiments have been performed at three different discharge densities: $\rho_{g}=10,25$ and $40 \mathrm{~kg} / \mathrm{m}^{3}$ to represent the internal conditions found in current production diesel engines. The test rig is a closed-loop and the flow passes through a honeycomb-type structure to force a coaxial velocity (lower than $2 \mathrm{~m} / \mathrm{s}$ ) of gas and clean up the testing section with remaining droplets of previous injection events.

A common-rail system was used to generate the diesel sprays at injection pressures of $\mathrm{p}_{\text {inj }}=50$, 100 and $180 \mathrm{MPa}$. The DI diesel injector is equipped with an axially-drilled single-hole nozzle with a conical orifice $(k$-factor $=1.8$ (Potz et al. 2000)) so that the flow should be noncavitating (Payri et al. 2005). The nozzle has a nominal outlet diameter of $0.110 \mathrm{~mm}$ and hydro-erosion (HE) has been performed to smoothen corners and increase discharge capacities (HE value $=10$ \%) (Payri et al. 2005). A commercial diesel fuel has been used. The injection energizing time has been set to $1.5 \mathrm{~ms}$, generating actual injection durations ranging from approximately 2.0 to $2.5 \mathrm{~ms}$ (mainly driven by injection pressure); long enough to allow the spray to be fully developed at all testing conditions taking into account the visualization window size.

Due to its fluorescence properties: visible wavelength (peak absorption around $550 \mathrm{~nm}$ ) and high quantum yield (Williams et al. 1983), Rhodamine B has been selected to be added to the fuel as a fluorescent tracer. As Rhodamine B is not directly miscible with diesel fuel, it has been mixed with dimethyl sulfoxide (DMSO) and toluene (less than $4 \%$ in volume) to achieve a complete and stable dilution of the dye. The fuel has been doped with $12 \mathrm{mg} / \mathrm{l}$ of solid (powder) 
Rhodamine B, the fluid-mechanical characteristics of the fuel (density, viscosity and surface tension) have been measured before and after mixing and showed that the addition of Rhodamine B (as well as DMSO and toluene) did not affect any of these properties (to the limits of our measuring devices). Note that both the DMSO and toluene do not absorb light in the visible range, which means that the fluorescence signal of the fuel is only emitted by Rhodamine B.

\subsection{Light source and signals collection}

Both the fuel sprays (with and without Rhodamine B) are illuminated by a pulsed Nd:YAG laser (Continuum Surelite II). The fuel with Rhodamine B is excited via the second harmonic generator (SHG), thus producing a wavelength of $532 \mathrm{~nm}$ with a pulse energy of $200 \mathrm{~mJ}$. The third harmonic generator (THG) has been used to excite the natural fluorescence of the commercial diesel fuel at $355 \mathrm{~nm}$ and the pulse energy was $100 \mathrm{~mJ}$. Note that the energies are different due to losses in the harmonic generators, $100 \mathrm{~mJ}$ at $355 \mathrm{~nm}$ represents the higher energy for our laser. Pulse duration for both wavelengths has been measured and is about $5 \mathrm{~ns}$ (Full Width Half Maximum (FWHM)). The beam is steered to the experimental section thanks to laser-line mirrors and a thin $(80 \mu \mathrm{m})$, parallel, $48 \mathrm{~mm}$ wide laser sheet is generated by three cylindrical lenses.

The images have been acquired orthogonally to the laser sheet with a 12-bit CCD camera (PCO Sensicam) with $1376 \times 1040$ pixels resolution equipped with a $60 \mathrm{~mm}$ objective (f/2.8 Nikkor Lens). An interference filter centered on $532 \mathrm{~nm}(2 \mathrm{~nm}$ FWHM) has been used to record the Mie scattering in both cases (recording the weaker signal going through the THG for the $355 \mathrm{~nm}$ excitation as described by Pastor et al. (2002)). Regarding the acquisition of the fluorescence, a bandpass filter centered on $420 \mathrm{~nm}$ ( $50 \mathrm{~nm}$ bandwidth FWHM) has been used to acquire the natural fluorescence and a longpass filter with a cut-on wavelength of $570 \mathrm{~nm}$ and a transition width of $5 \mathrm{~nm}$ for the fuel doped with Rhodamine B. To use the dynamic range of the imaging system, neutral density filters have been placed to adjust the intensity of the Mie scattered light. 
The exposure time of the camera has been set as low as $1 \mu$ s to reduce the potential flare of the external environment, the actual exposure time of the images would be the laser pulse duration ( $5 \mathrm{~ns})$. The optical setup is sketched in figure 1. The timings for the injection, the camera and the laser are all controlled by a purposely-designed synchronization system. The pictures have been taken at different times after the start of injection (ASOI) in order to get the desired spray development and the results presented later are average of 100 injection events.

\section{FLUORESCENCE PROPERTIES}

The molecules that exhibit fluorescence have common chemical and physical characteristics such as their large molecular size, polycyclic structure, thus making them more rigid (Eckbreth 1988). Many components of the commercial fuels used in the thermal engines today, especially aromatics have these characteristics and most likely emit fluorescence when irradiated in the ultraviolet. The quantification of fluorescence intensities emitted by such fuels is difficult because several compounds with different photophysical and photochemical behaviors fluoresce at the same time (Schulz and Sick 2005). On the other hand, Rhodamine B is a kind of xanthene dye, its properties in terms of fluorescent emission mainly rely on solvent polarity, dye concentration and $\mathrm{pH}$ value of the mixture (Ko et al. 2006). In this section, the fluorescence properties are investigated; measurements of emission spectra, quantum yield, absorption coefficient and lifetime have been performed to analyze the potential of both experimental techniques from a chemistry-based theoretical approach.

The fluorescent emission signals have been determined using a photon-counting spectrofluorometer (Photon Technology International, QuantaMaster 40) with excitation wavelengths of 355 and $532 \mathrm{~nm}$. Figure 2 presents the fluorescent emission signals together with the respective excitations used during these tests (signal intensities are normalized); the 
spectra of the filters used to collect the fluorescence signals are displayed and the graphic shows that there is no overlap.

As described in the theoretical background (section 2), the fluorescence quantum yield $\Phi$ is given as the ratio of the number of photons emitted over the number of photons absorbed by the sample. An easy way to determine the quantum yield of a fluorophore is to compare it to a standard with a known quantum yield. The quantum yield of the Rhodamine B dissolved in water has been investigated in detail and is commonly taken as a reference (Magde et al. 1999). Then, the fluorescence quantum yield can be calculated as follows (Williams et al. 1983):

$$
\Phi=\Phi_{\mathrm{R}} \frac{\mathrm{I}}{\mathrm{I}_{\mathrm{R}}} \frac{\tau_{\mathrm{R}}}{\tau} \frac{\mathrm{n}^{2}}{\mathrm{n}_{\mathrm{R}}^{2}}
$$

Where $\Phi$ is the quantum yield, I the intensity integrated under the emission spectrum, $\mathrm{n}$ is the refractive index, and $\tau$ is the optical depth as described in section 2 . The subscript $R$ refers to the values obtained for the reference sample used in this experiment: Rhodamine B dissolved in water. The values of the refractive indices used for the calculation were: $n=1.463$ for the fuel doped with Rhodamine B at $\lambda=532 \mathrm{~nm}$ and 1.477 for the commercial fuel at $355 \mathrm{~nm}$. Note that the difference in refractive index is due to distinct wavelengths as both fuels are issued from the same commercial fuel. The optical depths have been measured by placing the two solutions into optical cuvettes, the intensity signals have been recorded by a photo-diode. The pulsed Nd:YAG laser described earlier in section 3 has been used as light source and the same interference filter $(532 \mathrm{~nm})$ has been used to be consistent with the imaging process. Note that the measurements done to characterize the fluorescence quantum yield of the fuels have been performed at ambient condition ( $1 \mathrm{~atm}$ and $293 \mathrm{~K}$ ). The results of the quantum yield measurements are $\Phi=0.70$ for the fuel doped with Rhodamine B and 0.08 for the natural fluorescence of the fuel, at the corresponding wavelengths and over the acquisition spectra. The quantum yield of the natural fluorescence of the fuel is almost 9 times lower than that of the Rhodamine B and must lead to a 
significant decrease in fluorescence intensity; this will be analyzed and discussed in the next section.

The absorption coefficient of the fluids used have been investigated by measuring the optical depth of the media by recording the intensity loss of a laser beam going through the absorbing liquid along a pathway as described in equation 2. Optical cells of different path-lengths have been filled with the fuels; the equipment described in section 3 has been used and the light intensity decays have been recorded with a photo-diode as described in the previous paragraph concerning the quantum yield measurements. At $532 \mathrm{~nm}$, the absorption coefficient has been measured to be $\alpha=230 \mathrm{~m}^{-1}$ for the fuel doped with $12 \mathrm{mg} . \mathrm{l}^{-1}\left(2.07 \times 10^{-5}\right.$ mol. $\left.\mathrm{l}^{-1}\right)$ of Rhodamine $\mathrm{B}$ and $\alpha=0.823 \mathrm{~m}^{-1}$ for the pure fuel (the coefficient of determination of the fitting was higher than $99 \%$ for both cases). This value of the absorption coefficient should be high enough to avoid Morphology Dependent Resonance (MDR); phenomenon observed by other authors for low dye absorption which leads to over estimating the droplet size for this kind of experiment (Chen et al. 1996, Barnes et al. 1994). For the natural fluorescence, excited at $355 \mathrm{~nm}$, the value of the absorption coefficient is $\alpha=1660 \mathrm{~m}^{-1}$. These results mean that the absorption is almost 8 times higher for the pure fuel than for the fuel doped with Rhodamine B when both are excited at their corresponding wavelengths.

Another parameter has been measured too: the fluorescence lifetime. This parameter is generally considered independent of the emission initial intensity. The fluorescence lifetime of the different dyed fuels has been measured by a spectrofluorometer (PTI, TimeMaster LED TM20). The lifetime is commonly measured at half the maximum intensity, in other words, the full width half maximum of the fluorescent signal as a function of time. In the following expression (eq. 5), $\Gamma$ is the decay rate which is the inverse of the fluorescence lifetime, and $I_{f}$ is the intensity of the fluorescence signal with respect to time $t$ : 


$$
I_{f}(t)=I_{f i t=0)} \cdot e^{-\Gamma t}
$$

The time-resolve fluorescent emission signals are plotted in figure 3 together with the excitation. Note that the results have been obtained at the specific wavelength corresponding to the maximum fluorescence intensity: it means $440 \mathrm{~nm}$ for the natural fluorescence and $590 \mathrm{~nm}$ for the fluorescence emitted by Rhodamine B (cf. Figure 2). The excitation wavelengths have been set to be the same as those used during the spray experiments: $355 \mathrm{~nm}$ for the natural fluorescence and $532 \mathrm{~nm}$ for the fuel with Rhodamine B. The real fluorescence emissions are obtained after subtraction of the excitation; the results of the fluorescence lifetime are $3.6 \mathrm{~ns}$ and 9.1 ns for the fuel with Rhodamine B and for the commercial fuel emitting natural fluorescence, respectively. The lifetime of the natural fluorescence of the fuel is between two and three times longer than that of the Rhodamine B added to the fuel. Such a long fluorescence lifetime generally means the presence of several fluorophores that can potentially behave differently under different conditions (such as pressure and temperature). This means that the fluorescent emission may not behave the same depending on temperature and pressure. This could have an impact on the shape of the fluorescence intensity presented in figure 2 for real spray experiments under different pressure and temperature conditions. On the other hand, it has been observed that the xanthenes dyes such as Rhodamine B are affected by temperature variations, therefore inducing quenching of the fluorescent emission (Ko et al. 2006). This means that the intensity of the fluorescent emission would decrease when temperature increases; however, the intensity profile would not change (Ko et al. 2006, Sjoback et al. 1998).

\section{COMPUTATIONAL ANALYSES}

The purpose of this work is to compare two different approaches to spatially measure the droplet size distribution with the LIF/Mie principle. The scattered light must be proportional to 
the surface and the fluorescence intensity to the volume of the droplets. The proportionalities have been verified by calculation thanks to the previously measured parameters (section 4).

\subsection{Scattered light vs. droplet surface}

In this study, the scattered light is always acquired at $532 \mathrm{~nm}$. The regular diesel fuel used has really low light absorption this wavelength, so the light scattered by the fuel droplets when doped with Rhodamine B will have a different behavior due to absorption. To apply LSD (Laser Sheet Dropsizing) in sprays, it is assumed that droplet diameter is related to the scattered light intensity such that: $I_{S}=k \cdot D^{2}$ (with $D$ the droplet diameter).

The intensity of the light scattered by a droplet illuminated by a single beam of parallel rays has been studied by many authors and generally shows good agreement (LeGal et al. 1999, Domann and Hardalupas 2000). However, as the wavelength used to record the Mie scattering is different to that used to excite the natural fluorescence of the commercial fuel, the droplet surface dependency has been computed using the Mie theory as verification. The simulation reproduces the experimental setup with the signals acquired by the CCD placed at $90^{\circ}$ from the laser sheet with a full collection angle of the imaging system is approximately $60 \mathrm{mrad}$ (with the lens diaphragm on the $f / 2.8$ position). The intensity of the scattered light presented in figure 4 is an integration over the area of emission (of a droplet) collected by the objective and recorded by the sensor used in this work.

The intensity versus droplets diameter has been fitted for both configurations, the intensity of the scattered light agrees almost perfectly with the square of the droplet diameter. The exponent coefficient has been found to be 2.000 for both cases for droplet diameter ranging from 1 to 100 $\mu \mathrm{m}$. 


\subsection{Fluorescence intensity vs. volume}

The fuel mass fraction of a liquid jet can be assumed and acquired only when the intensity of the fluorescence signal is linearly dependent to the cube of the droplet diameter. This dependency has been deeply studied by several authors (LeGal et al. 1999, Domann and Hardalupas 2001) and their findings showed that the exponent on the diameter of the droplets depends on the concentration of fluorescent dye present in the liquid. If the absorption coefficient of the fuel is too high (for high dye concentration), the intensity of light within the droplet is not heavenly distributed (due to absorption on the way) and consequently affects the intensity of the signal emitted. The result of this is that the measurements done generally underestimate the actual mass of fluorophore present in the droplet and thus the $D^{3}$ dependency is not respected.

The fluorescence signal intensity dependence with cubic exponent of droplet diameter such that: $I_{F}=K . D^{3} ;$ has been computed taking into account the absorption of light over the $1^{\text {st }}, 2^{\text {nd }}$ and $3^{\text {rd }}$ paths in the droplet, although it has been observed that the contribution of $2^{\text {nd }}$ and $3^{\text {rd }}$ orders of scattering was nearly negligible as described by Domann and Hardalupas (2001). Figure 5 shows the results of the calculation of the fluorescence intensity vs. droplet diameter; like for the scattered light, a similar approach with a fitting is used to evaluate the exponent on the diameter to follow the calculation.

The exponents on the diameter shall be equal to 3 to get the intensity dependent to droplet volume/mass; however the fitting of the intensity for the regular fuel shows an exponent as low as 2.819 which obviously induce errors on the measurements. Besides, the exponent computed for the fuel doped with Rhodamine B is relatively close to 3 with a value of 2.996 . This difference between the exponents comes from the high absorption of the regular fuel at the excitation wavelength $(355 \mathrm{~nm})$, this leads to absorption of the beams through the droplet and so the distribution of light in the droplet is not uniform. Other researchers have noticed this behavior for elevated dye concentration making the absorption coefficient high (LeGal et al. 
1999). With these values (over the range $1-100 \mu \mathrm{m}$ in droplet diameter), the maximum error made on the volume is about $3 \%$ for the fuel with Rhodamine B and can go up to $21 \%$ when the natural fluorescence of the fuel is recorded.

\section{RESULTS AND DISCUSSIONS}

As it was defined before, the main objective of this work is to compare two experimental solutions to evaluate the droplet size distribution in DI Diesel sprays. It has been stated earlier that both Mie signals should not be different due to acquisition at the same wavelength and solid surface dependence behavior. Some difference however must be expected on the fluorescence side. Figure 6 presents two ensemble-average images of the signals emitted by the natural fluorescence of the commercial fuel (labeled A) and for that emitted by the Rhodamine B added to the fuel (labeled B). These images have been recorded at the intermediate condition: injection pressure of $100 \mathrm{MPa}$ and discharge density of $25 \mathrm{~kg} / \mathrm{m}^{3}$. The signals have been normalized and a color map has been applied to make the comparison of the signals straight forward; note that the laser sheet enters the image from the bottom On these two images, it looks like the natural fluorescence signal presents a dissymmetrical behavior, while it is not visually the case for the signal emitted by the Rhodamine B.

To further analyze this feature, figure 7 represents the normalized intensity profiles of the fluorescent emission measured radially at a distance of $30 \mathrm{~mm}$ from the tip. The purpose of this figure being to visually show the dissymmetrical behavior of the spray, it is necessary to accurately locate the spray axis. To account for spray mistargeting (if pointing off-axis for example), the axis has been evaluated through macro-visualization of the spray using the same installation and conditions replacing the laser illumination by xenon flash lamps lighting the spray from both sides. The axis plotted in figure 7 (and the following) corresponds to the angle bisector over an average of 100 images. Looking at the natural fluorescence signal intensity 
plotted in figure 7, it appears that the curve shows distinct distributions on both sides of the spray axis. The area below the curve seems to be higher on the right side of the axis of the spray (laser sheet enters from the right side) rather than on the left side. This behavior has already been observed by Pastor et al. (2002) who applied the Planar Laser-Induced Fluorescence technique to quantify fuel concentration in a diesel spray using the natural fluorescence of a commercial fuel. They also reported this dissymmetry on the natural fluorescence signal. The difference in terms of signal intensity between one side of the spray axis and the other has been estimated by calculating a dissymmetry ratio $\left(D_{R}\right)$, considering $I_{R}$ the intensity of the recorded signal along the radial profile such that (Pastor et al. 2002):

$$
\mathrm{D}_{\mathrm{R}}=100 .\left|\int_{\mathrm{B} \% \mathrm{t}}^{\mathrm{Axls}} \mathrm{I}_{\mathrm{R}}-\int_{\text {Axls }}^{\mathrm{T} \% \mathrm{I}} \mathrm{I}_{\mathrm{R}}\right|
$$

A symmetrical spray, as it is to expect, should return $D_{R}=0$. The symmetrical behavior of such sprays is commonly accepted and has been purposely investigated by Desantes et al. (2007). In the example presented in figure 6 , the dissymmetry ratio of the fluorescent emission is $12.1 \%$. These values are equivalent to those found by Pastor et al. (2002) when the natural fluorescence of the diesel fuel is acquired, reporting errors up to $25 \%$. On the other hand, the profile for the LIF of Rhodamine B appears more similar in terms of intensity distribution on both sides of the axis. The dissymmetry ratio also confirms this visual impression as $D_{R}$ is only $4.6 \%$ for fluorescence signals when the fuel is doped with Rhodamine $B$, this value about three times lower than that calculated for the natural fluorescence. Table 1 reports the dissymmetry ratio $\left(D_{R}\right)$ for the LIF signals for both techniques under the different operating conditions explored in this study.

The results clearly show different behavior between the two fluorescence signals and demonstrate the relationship between fluorescence properties and signals recorded by the experimental arrangement. The high absorption coefficient of the commercial fuel when excited 
at $355 \mathrm{~nm}$ seems to be a good explanation for this observation. On the other hand, as Mie scatter signal is acquired at $532 \mathrm{~nm}$ for both techniques, where the absorption is really low, the difference between LIF and elastic scattering would be even more important. This must have an impact when the LIF/Mie ratio is done to get a map of droplet diameter as the absorption is not the same for both signal. It is interesting to observe that both techniques present higher dissymmetry when the injection pressure goes up.

To obtain two-dimensional results of the droplet diameter (SMD), a calibration is necessary. A phase Doppler instrument (TSI - FSA 4000) has been used for this purpose; the measurements have been performed at $30 \mathrm{~mm}$ downstream on the edge of the spray. The results of the measurements done with the PDPA instrument, as well as the set up and calibration are made available by Soare (2007) and Payri (2008). Radial profiles of the SMD at $30 \mathrm{~mm}$ from the tip obtained with both techniques are presented in figure 8 and set against the results of the PDPA instrument used for the calibration of the techniques. As observed and commented along the last paragraphs, a dissymmetry is also shown on the droplet diameter when the natural fluorescence is acquired and coupled to the Mie signal at $532 \mathrm{~nm}$. When using two signals recorded at different wavelength, the propagation of light is not the same and therefore no compensation of the asymmetrical behavior of the scattered light within the spray is achieved. Another observation confirming this interpretation of the results is that such dissymmetry does not appear for the signals acquired and ratioed when Rhodamine B has been added to the fuel. This is in line with previous works published in this field, stating that good agreements were observed when comparing measurements from the interferometric technique and the LIF/Mie ratio (PDS) (LeGal 1999).

For the different reasons detailed in the last paragraphs, the solution using the Rhodamine B as a fluorescent tracer is preferred over the natural fluorescence emitted by the commercial fuel used in this study. Figure 9 presents two-dimensional maps of the Sauter Mean Diameter for different times ASOI, showing the development of the spray under the intermediate condition (injection 
pressure of $100 \mathrm{MPa}$ and discharge density of $25 \mathrm{~kg} / \mathrm{m}^{3}$ ). The radial distribution of SMD for the steady part of the spray at $30 \mathrm{~mm}$ is presented in figure 8 . The steady region means that the head of the spray is relatively far downstream that location; in this example, the time ASOI was 1.55 ms (not shown in figure 9) to ensure stability of the droplet size distribution. Larger droplets on the centerline of the spray can be observed on this figure all the way during the development. This observation has been reported by many authors employing different experimental techniques to obtain droplet diameter (Sankar et al. 1999, Albrecht et al. 2003, Soare 2007). Bigger droplets on the centerline can be explained by spray momentum being higher in the center of the spray, thus experiencing less disturbances, leading to droplet aggregation generally called coalescence.

The influence of injection pressure on droplet diameter has also been highlighted in several studies, in which the authors reported a decrease in droplet diameter for an increase in injection pressure (Albrecht et al. 2003, Soare 2007). Figure 10 plots the radial distribution of SMD for two injection pressures: $50 \mathrm{MPa}$ (labeled A) and $180 \mathrm{MPa}$ (labeled B); these results report the droplet diameter at a discharge density of $25 \mathrm{~kg} / \mathrm{m}^{3}$ for two distances from the injector tip: 20 and $40 \mathrm{~mm}$. First observation is that the droplet size is higher in the center for both injection pressures and axial positions as seen in figure 8. Another comment valid for both injection pressures is that although the droplet diameters on the edges are very similar, the droplets are bigger on the centerline for shorter distance from the tip. This is not surprising as smaller droplets are expected downstream due to on-going atomization; in addition, the difference in SMD between the two locations is lower for the highest injection pressure (180 MPa vs. 50 MPa). More complete atomization is expected at the same location due to higher aerodynamic forces for the higher injection pressure as higher velocities would enhance droplet breakup (Im et al. 2011, Soare 2007). Higher atomization level mainly results in lower droplet diameter for higher injection pressure as referenced by the y-axes on figure 10. At the same time, at high injection pressure (fig. 10B), the SMD distributions do not appear symmetrical, while it is the case for the low injection pressure (fig. 10A). This has to be related with better atomization and 13 (issue 5), pp. 713-724, doi 10.1007/s12239-012-0070-z 
smaller droplet size for higher injection pressure as described above. One explanation is that smaller droplets might affect the scattering of light as the optical depth should increase slightly, considering constant liquid volume fraction as reported by Payri et al. (2011). This comes from a different behavior of the internal scattered light signal due to smaller scatterers and higher number density (droplet concentration per unit volume). The optical depth being higher, the extinction throughout the spray is too important, thus leading to low signal-to-noise ratio when LIF and Mie signal are ratioed.

The density of the ambient gases in which the spray is injected is known to affect macroscopic parameters such as tip penetration and spreading angle widely (Payri et al. 2005). The influence of discharge density is really important when it comes to droplet diameter as well. Figure 11 presents radial SMD distributions for two discharge densities: 10 and $40 \mathrm{~kg} / \mathrm{m}^{3}$. The injection pressure is $100 \mathrm{MPa}$ for both cases and similarly to figure 10, the distributions are plotted for two axial locations (20 and $40 \mathrm{~mm}$ ). Similar comments to those made on figure 10 can be repeated concerning the shape of the radial SMD distributions presented here. However, the main observation concerning these two graphs is the droplet diameter for both discharge densities: the droplets get bigger when discharge density increases. This has been observed by others (Albrecht et al. 2003, Soare 2007), although the explanations do not always agree, coalescence is commonly accepted to cause this. These two graphs also highlight the fact that the sprays do not spread the same when varying ambient density. When a spray is injected into low ambient density such as $10 \mathrm{~kg} / \mathrm{m}^{3}$, the spreading angle is relatively low, and the diameter of the spray is only slightly more than $2 \mathrm{~mm}$ at $20 \mathrm{~mm}$ from the tip. For higher discharge densities such as $40 \mathrm{~kg} / \mathrm{m} 3$ studied in this work, the spray is wider; with a diameter of about $7 \mathrm{~mm}$, it occupies more than 10 times the area of the lower discharge density spray. This obviously has an impact on droplet spatial distribution and their size: distanced droplets of larger diameter are generally observed in sprays injected under higher ambient densities, while droplets are smaller and closer for lower discharge density conditions. 
The main observations have been reported in the last paragraphs, nevertheless, to summarize the measurements performed in this work, table 2 provides the droplet diameter (SMD) for the different conditions. The values reported in this table correspond to the SMD measured by the LIF/Mie ratio on the centerline at $30 \mathrm{~mm}$. Note that measurements of the droplet diameter via a PDPA instrument are also available in ref. (Soare 2007) for the same testing conditions.

\section{CONCLUSIONS}

A technique using the natural fluorescence of a commercial diesel fuel has been successfully applied to current DI diesel sprays and compared with another solution acquiring the fluorescence signal of a tracer (Rhodamine B) added to the fuel. The analysis of the fluorescent emission properties used in both techniques showed that the quantum yield of Rhodamine B in the fuel was almost nine times higher than that of the natural fluorescence. Inversely, the absorption coefficient was almost eight times lower in the fuel with Rhodamine B than in the commercial diesel fuel. The calculation made to check droplet volume dependency with fluorescence intensity proved that the fluorescence signal of the commercial fuel did not follow this dependency for droplets up to $100 \mu \mathrm{m}$ in diameter.

The behavior of the signals when the techniques are applied to real isothermal sprays demonstrate the discrepancies observed theoretically as the radial profiles showed dissymmetry due to the high absorption and low quantum yield of the natural fluorescence. On the other hand, such distortion of the signal did not appear when the fluorescence signal emitted by the Rhodamine B is acquired. The dissymmetrical behavior of the natural fluorescence signal made this solution not reliable for quantification of the droplet diameter via LIF/Mie ratio. When adjusted with a PDPA instrument, the LIF/Mie ratios for the technique adding Rhodamine B to the fuel provided interesting results. The main results concern larger diameter on the centerline 
of the sprays injected in our facilities, smaller droplets for higher injection pressures and bigger droplets for increasing density of the ambient gases.

ACKNOWLEDGMENTS - This research has been funded in the frame of the project PROFUEL reference TRA2011-26293 from Ministerio de Ciencia e Innovación. The injectors are part of the ECN international project.

\section{REFERENCES}

Albrecht, H.E., Damaschke, N., Borys, M. and Tropea, C. (2003). Laser Doppler and Phase Doppler Measurement Techniques. Springer, Berlin.

Barnes, M.D., Whitten, W.B. and Ramsey, J.M. (1994). Enhanced fluorescence yields through cavity quantum-electrodynamic effects in microdroplets. Journal of the Optical Society of America B 11, 7, $1297-1304$

Benajes, J., Molina, S., Novella, R., Amorim, R., Ben Hadj Hamouda, H. and Hardy, J. (2010). Comparison of two injection systems in an HSDI diesel engine using split injection and different injector nozzles. International Journal of Automotive Technology 11, 139-146.

Charalampous, G. and Hardalupas, Y. (2011). Method to reduce errors of droplet sizing based on the ratio of fluorescent and scattered light intensities (laser-induced fluorescence/Mie technique). Applied Optics 50, 3622-3637.

Chen, G., Mazumder, M., Chang, R.K., Swindal, J.C. and Acker, W.P. (1996). Laser diagnostics for droplet characterization: application of morphology dependent resonances. Progress in Energy and Combustion Science 22, 2, 163-188.

Desantes, J.M., Payri, R., Garcia, J.M. and Salvador, F.J. (2007). A contribution to the understanding of isothermal diesel spray dynamics. Fuel 86, 7-8, 1093-1101.

Domann, R. and Hardalupas, Y.A. (2000). Study of Parameters that Influence the Accuracy of the Planar Droplet Sizing (PDS) Technique. Part. Part. Syst. Charact. 3-11. 
Domann, R. and Hardalupas, Y.A. (2001). Spatial distribution of fluorescence within large doplets and its dependence on dye concentration. Applied Optics 40, 21, 3586-3597.

Domann, R. and Hardalupas, Y.A. (2002). Quantitative Measurement of planar Droplet Sauter Mean Diameter in sprays using Planar Droplet Sizing. Eleventh International Symposium on Application of Laser Techniques to Fluid Mechanics, Lisbon, Portugal.

Eckbreth, A.C. (1988). Laser Diagnostics for Combustion Species and Temperature. Abacus, Cambridge, Mass.

Greenhalgh, D.A. (1999). Planar measurements of fuel vapour, liquid fuel, liquid droplet size and soot. Planar Optical Measurement Methods for Gas Turbine Components, 1-7.

Im, K.; Lin, K.; Lai, M. \& Chon, M. (2011). Breakup modeling of a liquid jet in cross flow. International Journal of Automotive Technology 12, 489-496.

Jermy, M.C. and Greenhalgh, D.A. (2000). Planar dropsizing by elastic and fluorescence scattering in sprays too dense for phase Doppler measurement. Appl. Phys. B 71, 703-710.

Kim, Y., Kim, K. and Lee, K. (2011). Effect of a 2-stage injection strategy on the combustion and flame characteristics in a PCCI engine. International Journal of Automotive Technology 12, 639-644.

Ko, F.H., Weng, L.Y., Ko, C.J. and Chu, T.C. (2006). Characterization of imprinting polymeric temperature variation with fluorescent Rhodamine B molecule. Microelectronic Engineering 83, $864-868$.

Lakowicz, J.R.(2006). Principles of Fluorescence Spectroscopy, $3^{\text {rd }}$ edition. Springer.

Lee S.H., Teong, J., Lee, J.T., Ryou, H.S., Hong, K. (2005). Investigation on spray characteristics under ultra-high injection pressure conditions. International Journal of Automotive Technology 6, 2 125131.

Lee, B.; Song, J.; Chang, Y. \& Jeon, C. (2010). Effect of the number of fuel injector holes on characteristics of combustion and emissions in a diesel engine. International Journal of Automotive Technology 11, 783-791.

LeGal, P., Farrugia, N. and Greenhalgh, D.A. (1999). Laser sheet dropsizing of dense sprays. Optics and Laser Techn. 31, 75-83.

Lockett, R.D., Richter, J. and Greenhalgh, D.A. (1998). The characterisation of a diesel spray using combined laser induced fluorescence and laser sheet dropsizing. Conference on Lasers and ElectroOptics Europe.

Published as: INTERNATIONAL JOURNAL OF AUTOMOTIVE TECHNOLOGY 2012, Vol 13 (issue 5), pp. 713-724, doi 10.1007/s12239-012-0070-z 
Magde, D., Rojas, G.E. and Seybold, P. (1999). Solvent Dependence of the Fluorescence Lifetimes of Xanthene Dyes. Photochem. Photobiol. 70, 737.

Naber, J. and Siebers, D. (1996). Effects of gas density and vaporization on penetration and dispersion of diesel sprays. SAE Paper 960034.

Pastor, J.V., López, J.J., Juliá, J.E. and Benajes, J.V. (2002). Planar Laser-Induced Fluorescence fuel concentration measurements in isothermal Diesel sprays. Opt. Express 10, 7, 309-323.

Pastor, J.V., Payri, R., Araneo, L. and Manin, J. (2009). Correction method for droplet sizing by laserinduced fluorescence in a controlled test situation. Optical Engineering 48, 1, 013601.

Payri, R., Garcia, J.M., Salvador, F.J. and Gimeno, J. (2005). Using spray momentum flux measurements to understand the influence of diesel nozzle geometry on spray characteristics. Fuel, 84, 551-561.

Payri, R., Salvador, F.J., Gimeno, J. and Soare, V. (2005). Determination of diesel sprays characteristics in real engine in-cylinder air density and pressure conditions. J. Mech. Sci. Technol. 19, 2040-2052.

Payri, R., Tormos, B., Salvador, F.J., Araneo, L. (2008), Spray droplet velocity characterization for convergent nozzles with three different diameters, Fuel, 87, ( 15), 3176-3182.

Payri, F., Pastor, J., Payri, R. and Manin, J. (2011). Determination of the optical depth of a DI Diesel spray. J. Mech. Sci. Technol. 25, 209-219.

Potz, D., Chirst, W. and Dittus, B. (2000). Diesel nozzle: The determining interface between injection system and combustion chamber. Conference on Thermo and Fluid-dynamic Processes in Diesel Engines, Valencia, Spain.

Ramírez, A.I., Som, S., Aggarwal, S.K., Kastengren, A.L., El-Hannouny, E.M., Longman, D.E. and Powell, C.F. (2009). Quantitative X-ray measurements of high-pressure fuel sprays from a production heavy duty diesel injector. Experiments in Fluids 47, 1, 119-134.

Schulz, C. and Sick, V. (2005). Tracer-LIF diagnostics: quantitative measurement of fuel concentration, temperature and fuel/air ratio in practical combustion systems. Progress in Energy and Combustion Science 31, 75-121.

Sjoback, R. and Nygren, J. and Kubista, M. (1998). Characterization of fluorescein--oligonucleotide conjugates and measurement of local electrostatic potential. Biopolymers 46, 445-453.

Soare,V. (2007). Phase Doppler measurement in diesel dense sprays: optimisation of measurements and study of the orifice geometry influence over the spray at microscopic level. PhD Thesis, E.T.S. Ingenieros Industriales. Universidad Politécnica de Valencia.

Published as: INTERNATIONAL JOURNAL OF AUTOMOTIVE TECHNOLOGY 2012, Vol 13 (issue 5), pp. 713-724, doi 10.1007/s12239-012-0070-z 
Williams, A.T.R., Winfield, S.A. and Miller, J.N. (1983). Relative fluorescence quantum yields using a computer controlled luminescence spectrometer. Analyst. 108, 1067.

Yeh, C.N., Kosaka, H. and Kamimoto, T.A. (1993). Fluorescence/Scattering Imaging Technique for Instantaneous 2-D Measurements of Particle Size Distribution in a Transient Spray. Proc. $3^{\text {rd }}$ Congr. on Opt. Part. Sizing, Yokohama, Japan, 335-361. 


\section{List of figures:}

Figure 1: Sketch of the optical setup used in this study.

Figure 2: Fluorescent emission spectra for the commercial fuel and the fuel doped with Rhodamine B and their respective excitations.

Figure 3: Fluorescence intensity decays for the fluorescence emitted by the fuel doped with Rhodamine B and for the natural fluorescence

Figure 4: Scattered light intensity vs. droplet diameter for regular fuel (A) and when doped with Rhodamine B (B)

Figure 5: Relative fluorescence intensity vs. droplet diameter for regular fuel (A) and when doped with Rhodamine B (B)

Figure 6: Ensemble-average images of the signals (normalized intensity) emitted by the natural fluorescence of the commercial fuel (A) and for that emitted by the Rhodamine B added to the fuel (B) $\left(p_{\text {inj }}=100 \mathrm{MPa}, \rho_{\mathrm{g}}=25 \mathrm{~kg} / \mathrm{m}^{3}\right)$.

Figure 7: Normalized intensity profiles of the fluorescent emission measured radially at a distance of $30 \mathrm{~mm}$ from the tip $\left(\mathrm{p}_{\text {inj }}=100 \mathrm{MPa}, \rho_{\mathrm{g}}=25 \mathrm{~kg} / \mathrm{m}^{3}\right)$.

Figure 8: Radial profiles of the SMD at $30 \mathrm{~mm}$ from the tip obtained with both techniques as well as the corresponding results of the PDPA instrument ( $\left.p_{\text {inj }}=100 \mathrm{MPa}, \rho_{\mathrm{g}}=25 \mathrm{~kg} / \mathrm{m}^{3}\right)$.

Figure 9: 2-D maps of the Sauter Mean Diameter for different times ASOI $\left(\mathrm{p}_{\mathrm{inj}}=100 \mathrm{MPa}, \rho_{\mathrm{g}}=\right.$ $25 \mathrm{~kg} / \mathrm{m}^{3}, \mathrm{SMD}$ in $\left.\mu \mathrm{m}\right)$.

Figure 10: Radial distribution of SMD for two injection pressures: $50 \mathrm{MPa}(\mathrm{A})$ and $180 \mathrm{MPa}$ (B) at two distances from the tip: 20 and $40 \mathrm{~mm}\left(\rho_{\mathrm{g}}=25 \mathrm{~kg} / \mathrm{m}^{3}\right)$.

Figure 11: Radial distribution of SMD for two discharge densities: $10 \mathrm{~kg} / \mathrm{m}^{3}$ (A) and $40 \mathrm{~kg} / \mathrm{m}^{3}$ (B) at two distances from the tip: 20 and $40 \mathrm{~mm}\left(\mathrm{p}_{\mathrm{inj}}=100 \mathrm{MPa}\right)$. 


\section{List of tables:}

Table 1: Ratio of dissymmetry for the radial profiles of the fluorescence signals for the commercial fuel and the fuel with Rhodamine B (see eq. 6).

Table 2: Values of the Sauter Mean Diameter on the centerline at $30 \mathrm{~mm}$ from the tip measured by the LIF/Mie ratio and adjusted via PDPA measurements. 


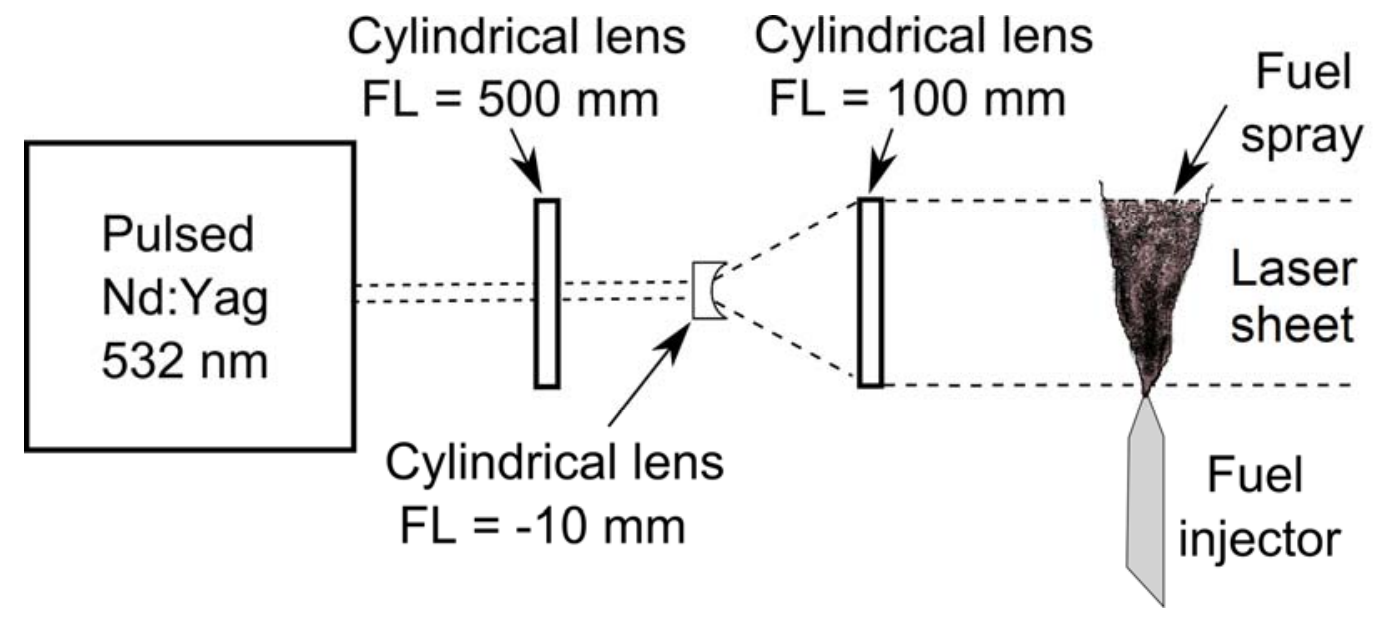

Figure 1

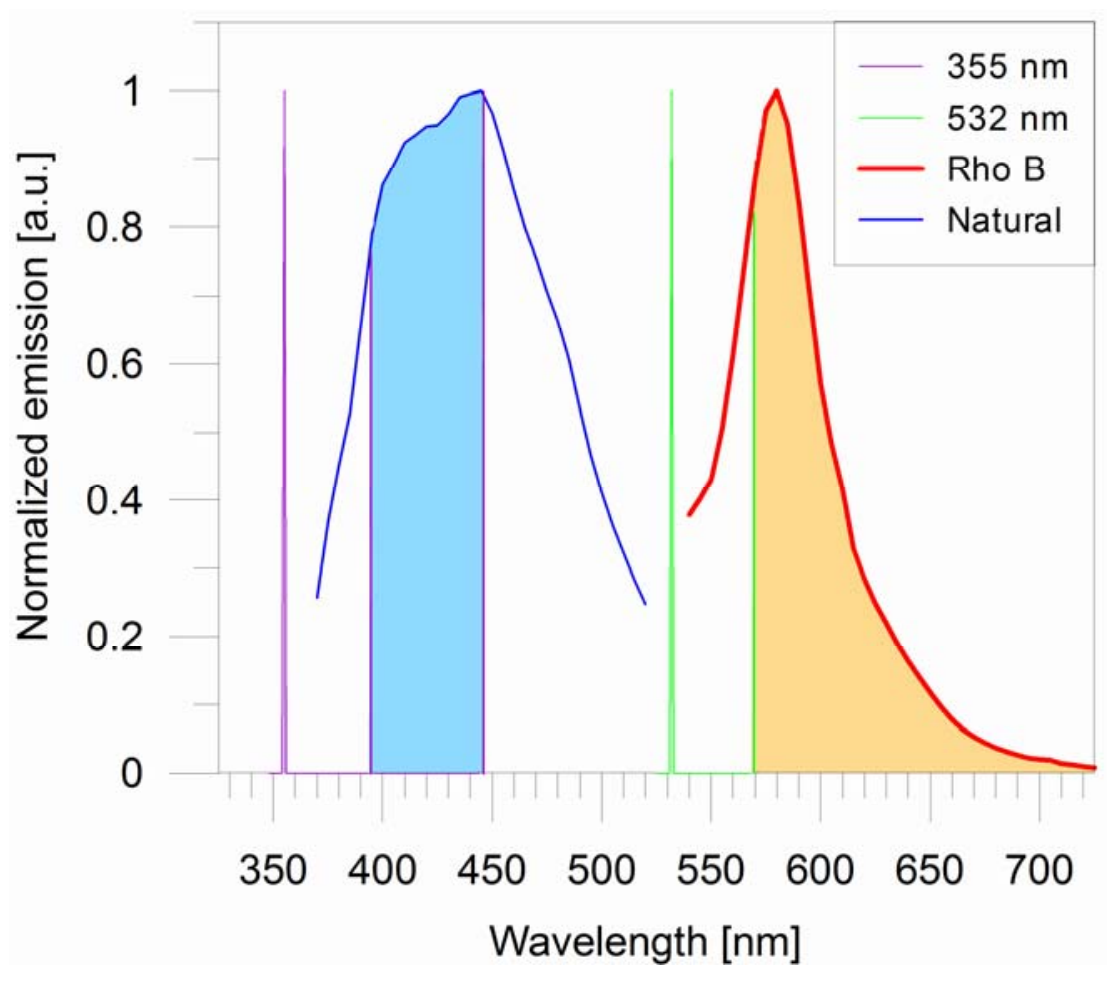

Figure 2

Published as: INTERNATIONAL JOURNAL OF AUTOMOTIVE TECHNOLOGY 2012, Vol 13 (issue 5), pp. 713-724, doi 10.1007/s12239-012-0070-z 


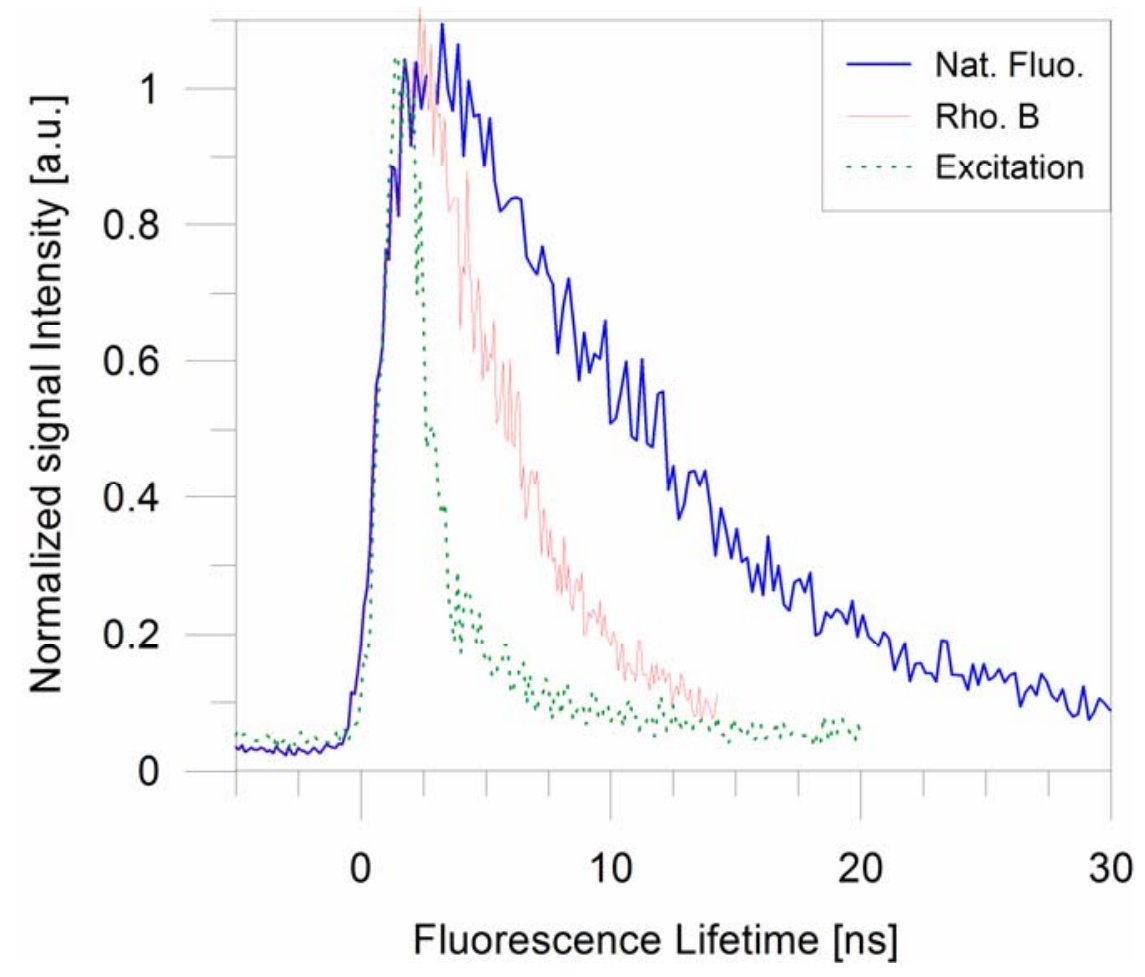

Figure 3 

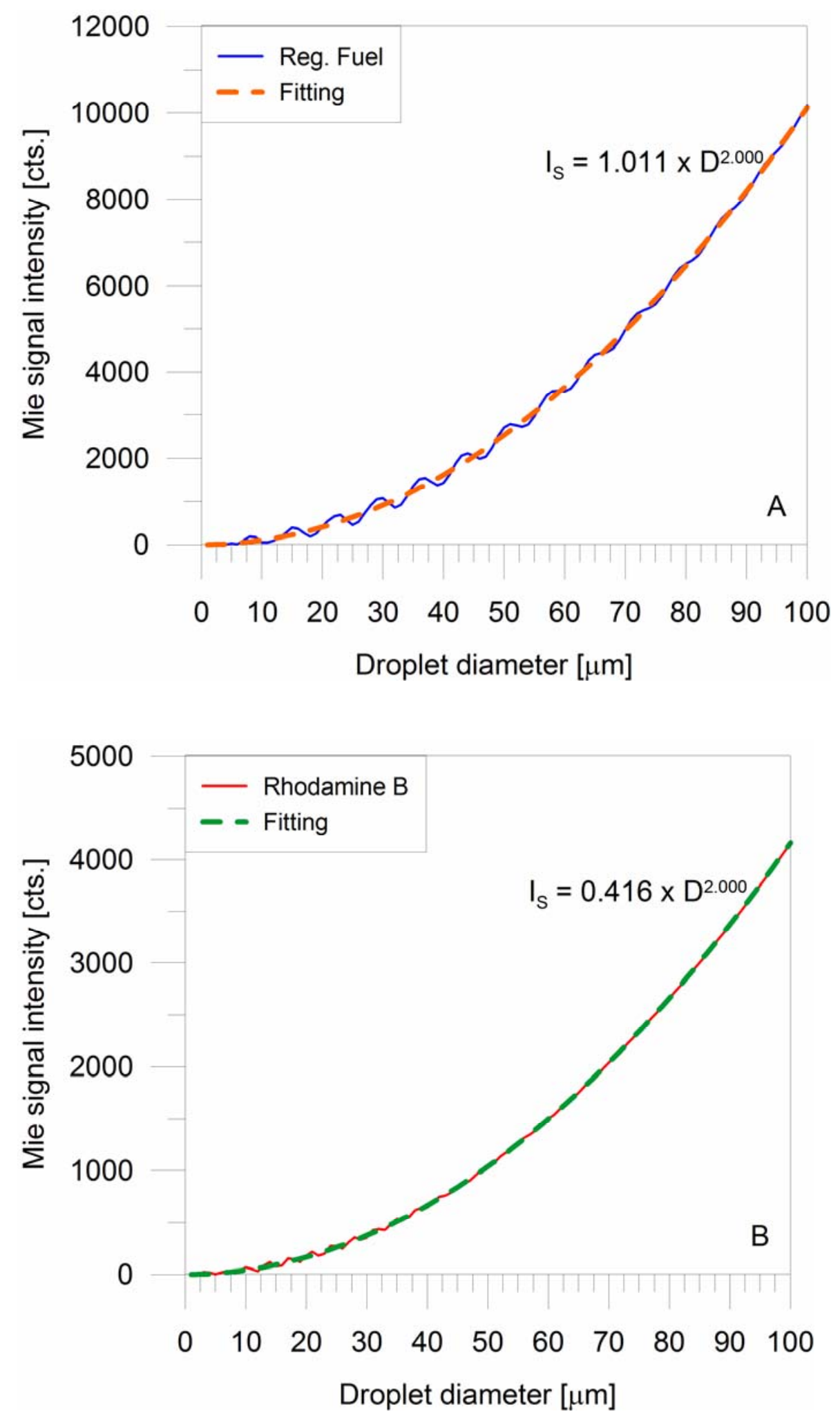

Figure 4 

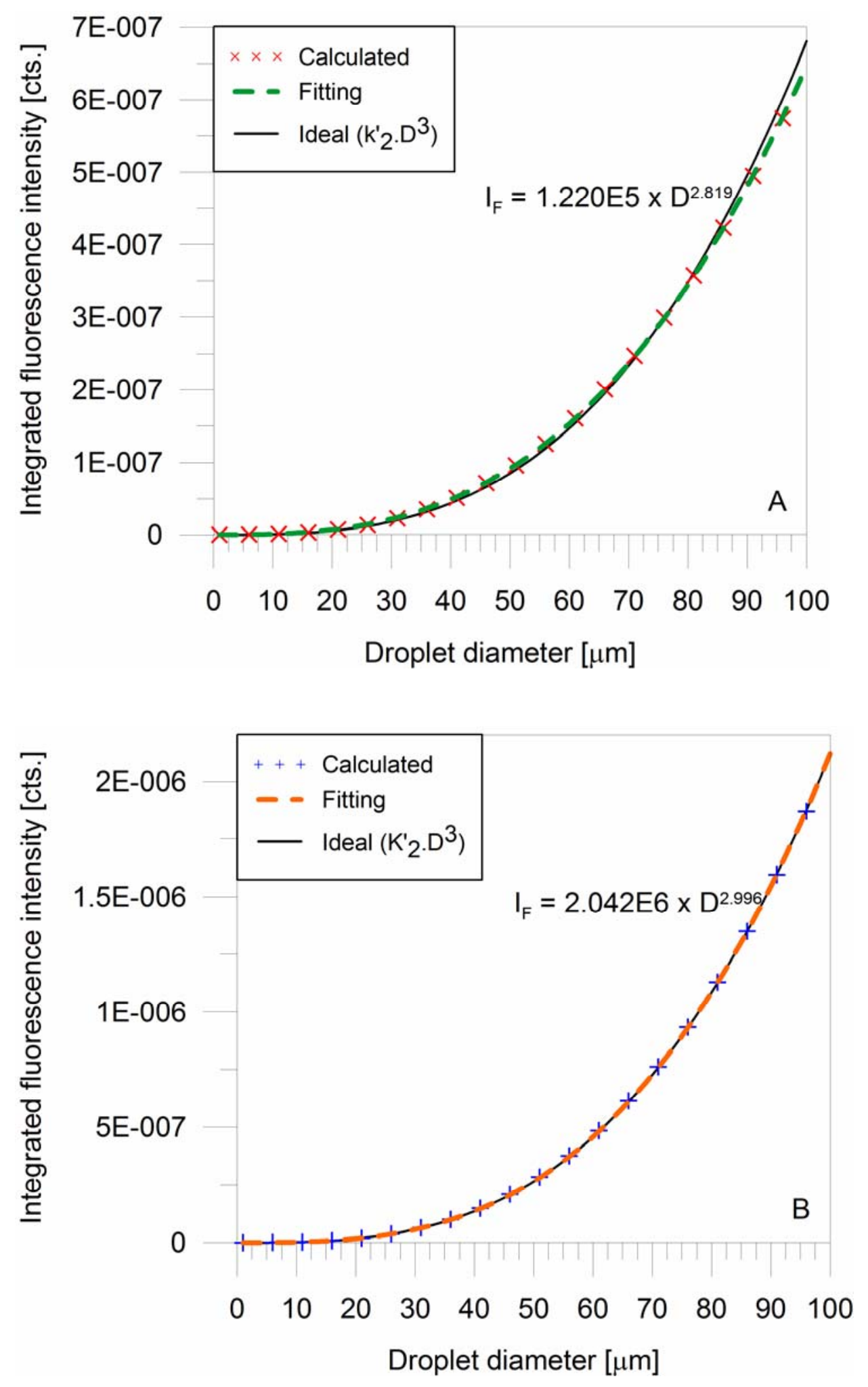

Figure 5

Published as: INTERNATIONAL JOURNAL OF AUTOMOTIVE TECHNOLOGY 2012, Vol 13 (issue 5), pp. 713-724, doi 10.1007/s12239-012-0070-z 


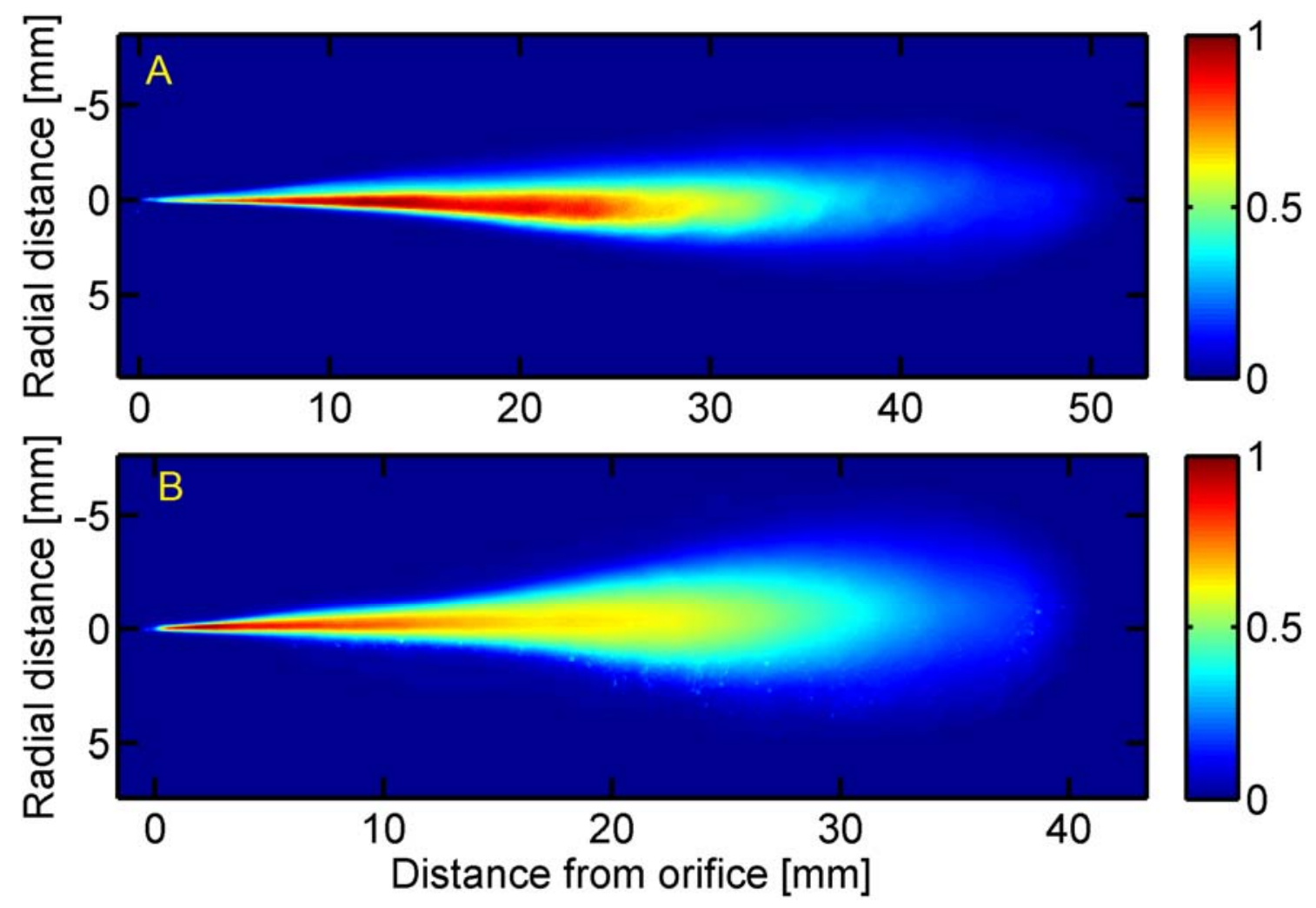

Figure 6 


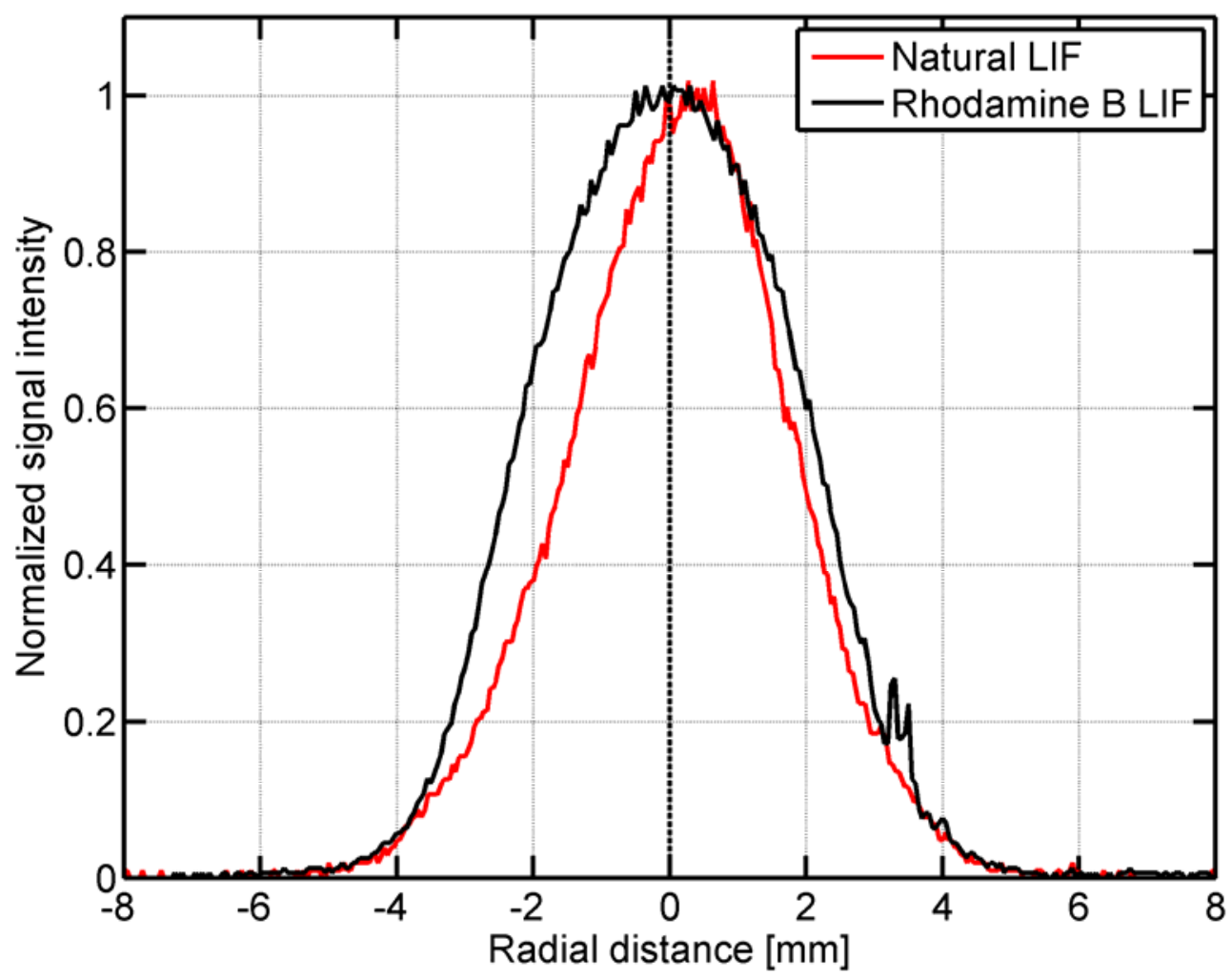

Figure 7

Published as: INTERNATIONAL JOURNAL OF AUTOMOTIVE TECHNOLOGY 2012, Vol 13 (issue 5), pp. 713-724, doi 10.1007/s12239-012-0070-z 


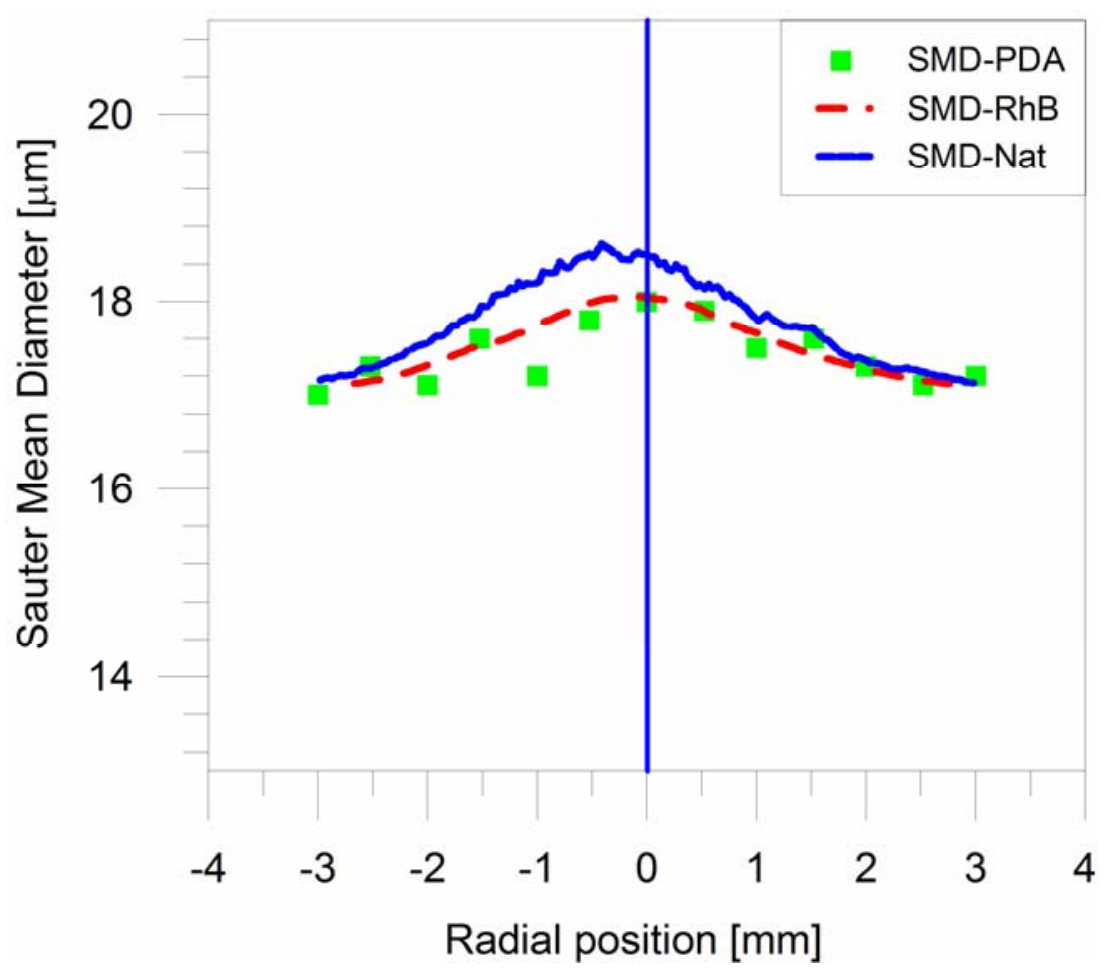

Figure 8 


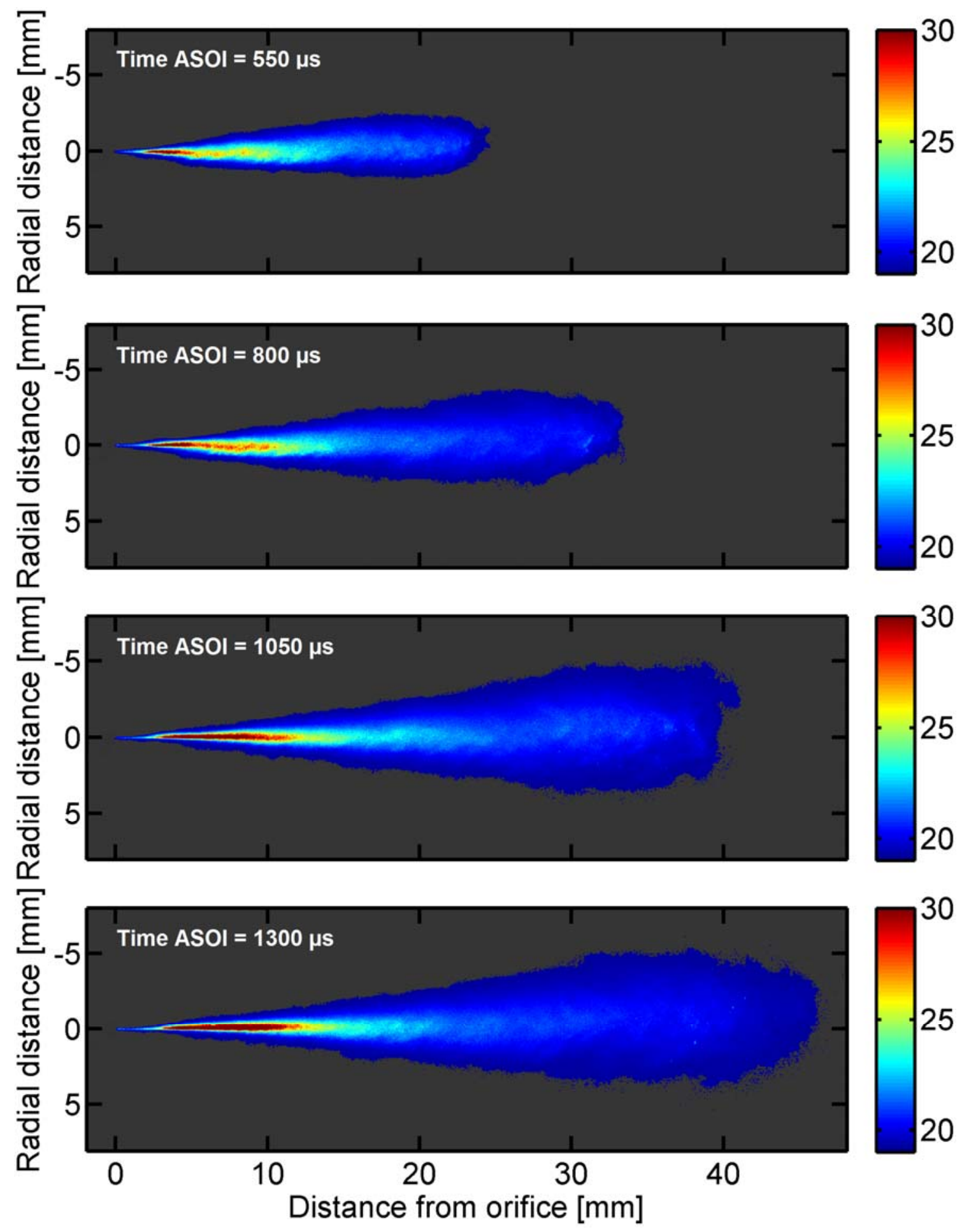

Figure 9

Published as: INTERNATIONAL JOURNAL OF AUTOMOTIVE TECHNOLOGY 2012, Vol 13 (issue 5), pp. 713-724, doi 10.1007/s12239-012-0070-z 

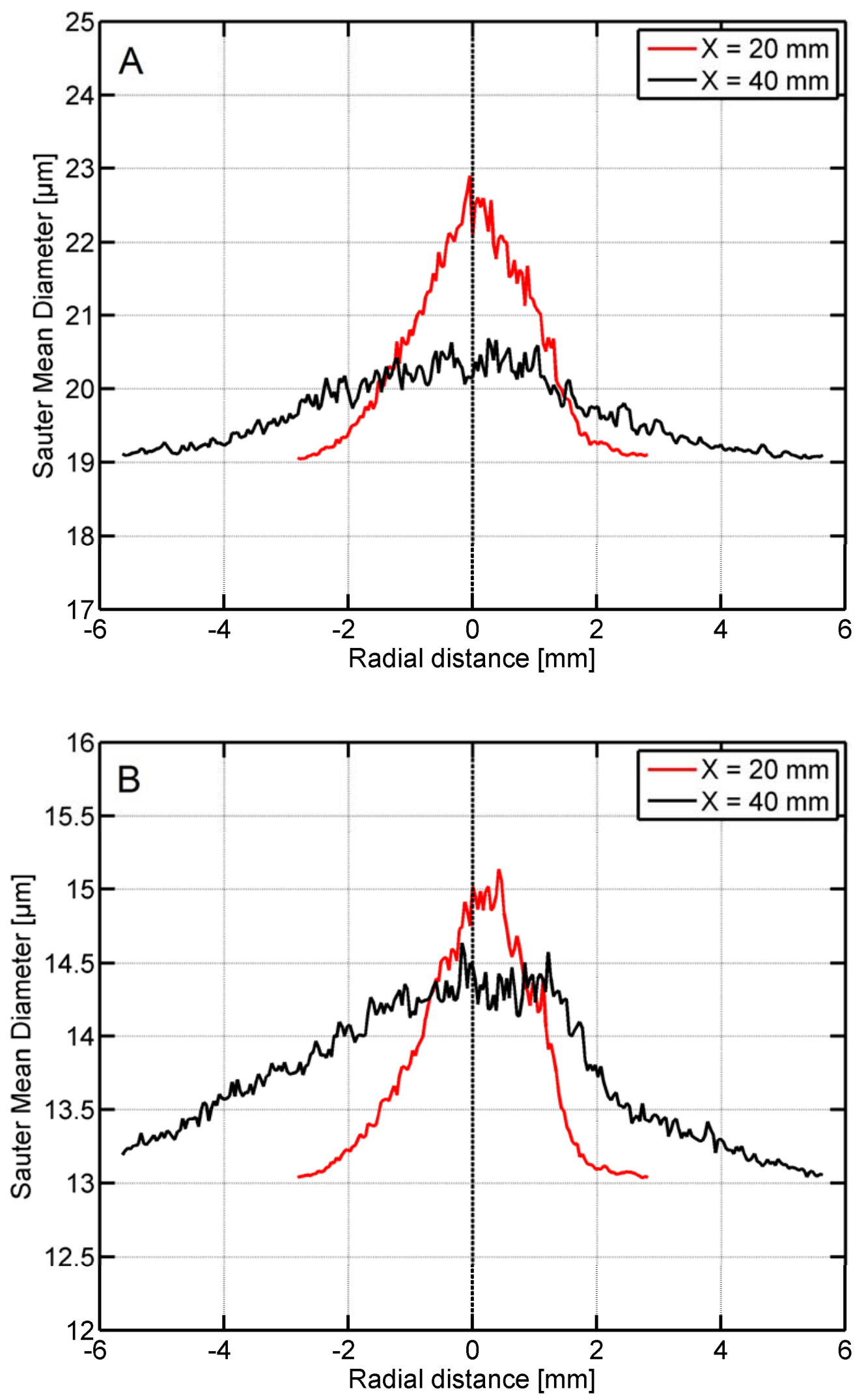

Figure 10

Published as: INTERNATIONAL JOURNAL OF AUTOMOTIVE TECHNOLOGY 2012, Vol 13 (issue 5), pp. 713-724, doi 10.1007/s12239-012-0070-z 

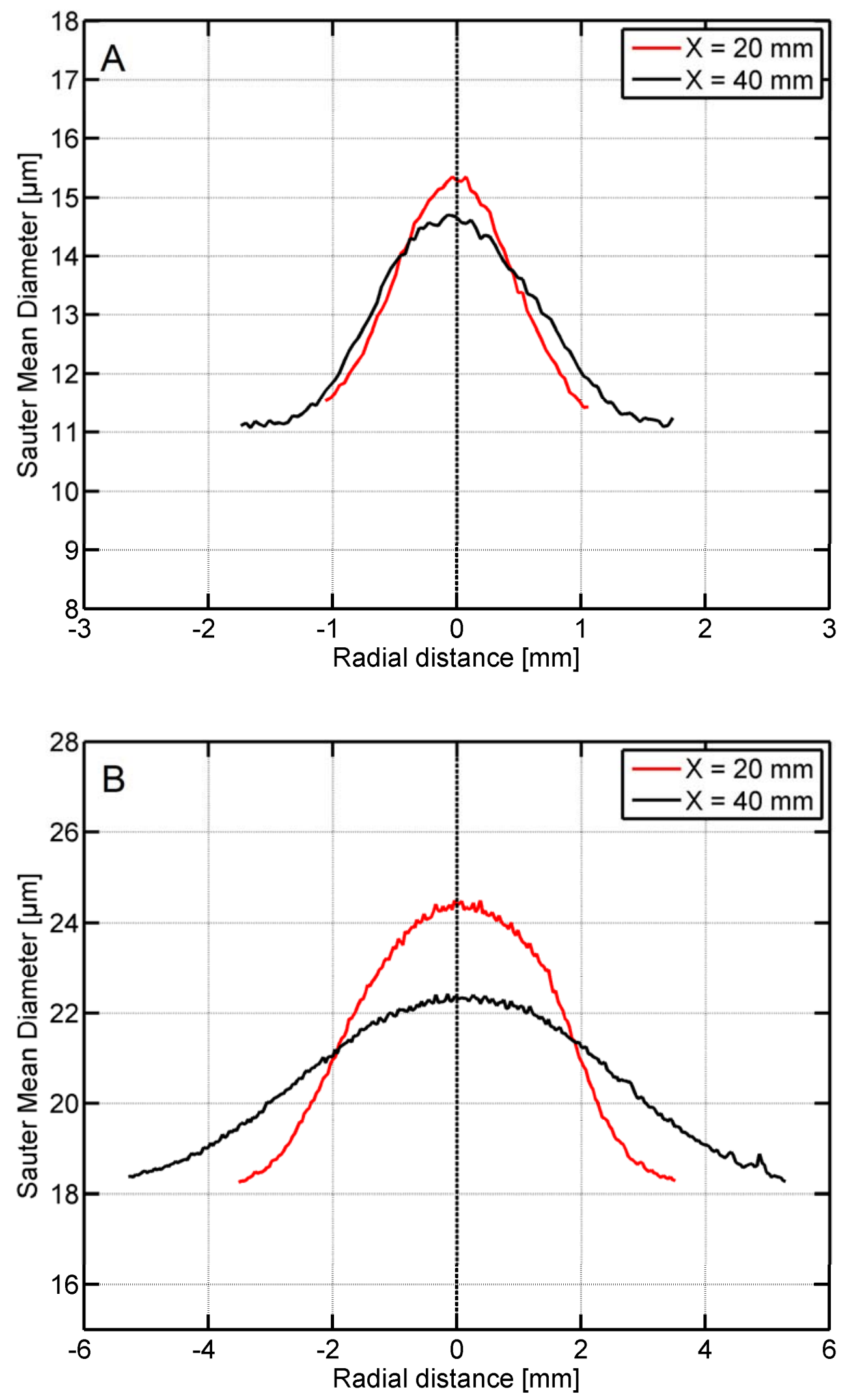

Figure 11

Published as: INTERNATIONAL JOURNAL OF AUTOMOTIVE TECHNOLOGY 2012, Vol 13 (issue 5), pp. 713-724, doi 10.1007/s12239-012-0070-z 
Table 1

\begin{tabular}{cccc}
\hline \multicolumn{4}{c}{ Diesel fuel (natural fluorescence) - $D_{\mathbf{R}}$ LF [\%] } \\
\hline$P_{\operatorname{mI}}$ & $10 \mathrm{~kg} / \mathrm{m}^{3}$ & $25 \mathrm{~kg} / \mathrm{m}^{3}$ & $40 \mathrm{~kg} / \mathrm{m}^{3}$ \\
\hline $50 \mathrm{MPa}$ & 7.3 & 4.5 & 4.1 \\
$100 \mathrm{MPa}$ & 11.7 & 12.1 & 9.3 \\
$180 \mathrm{MPa}$ & 13.0 & 14.9 & 11.1 \\
\hline \hline \multicolumn{4}{c}{ Diesel fuel + Rhodamine B - $D_{\mathrm{h}}$ UF [\%] } \\
\hline $\mathrm{P}_{\mathrm{inI}}$ & $10 \mathrm{~kg} / \mathrm{m}^{3}$ & $25 \mathrm{~kg} / \mathrm{m}^{3}$ & $40 \mathrm{~kg} / \mathrm{m}^{3}$ \\
\hline $50 \mathrm{MPa}$ & 7.5 & 1.0 & 2.1 \\
$100 \mathrm{MPa}$ & 7.9 & 4.6 & 3.1 \\
$180 \mathrm{MPa}$ & 12.0 & 8.3 & 5.6 \\
\hline
\end{tabular}

Table 2

\begin{tabular}{cccc}
\hline \multicolumn{4}{c}{ Sauter Mean Diameter [um] } \\
\hline $\mathrm{p}_{\text {imj }}$ & $10 \mathrm{~kg} / \mathrm{m}^{3}$ & $25 \mathrm{~kg} / \mathrm{m}^{3}$ & $40 \mathrm{~kg} / \mathrm{m}^{3}$ \\
\hline $50 \mathrm{MPa}$ & 18.7 & 21.4 & 28.5 \\
$100 \mathrm{MPa}$ & 15.0 & 18.1 & 23.3 \\
$180 \mathrm{MPa}$ & 12.8 & 14.7 & 20.0 \\
\hline
\end{tabular}

Published as: INTERNATIONAL JOURNAL OF AUTOMOTIVE TECHNOLOGY 2012, Vol 13 (issue 5), pp. 713-724, doi 10.1007/s12239-012-0070-z 